\title{
A TECNOLOGIA EDUCACIONAL E O LETRAMENTO DIGITAL NA ESCOLA PÚBLICA: ALGUM ESTRANHO NO NINHO?
}

Lívia M. T. Rádis Baptista

(Universidade Federal da Bahia)

Eliúde Costa Pereira

(Universidade Federal do Maranhão)

\section{RESUMO}

Os estudos sobre os letramentos têm apontado para a necessidade de redimensionamentos ontológicos e paradigmáticos quanto à compreensão das diversas práticas letradas e sua relação com os sujeitos na sociedade contemporânea e tal é o caso das práticas que envolvem as tecnologias e ambientes digitais no âmbito escolar. Assim, a fim de conhecer como o letramento digital vem sendo inserido nas práticas de linguagens, na educação básica, realizou-se uma investigação em uma escola pública, que oferta o Ensino Médio. Tratou-se de um estudo de caso, em que examinou a relação entre diferentes contextos condicionantes da inserção do letramento digital: o prescritivo e orientativo; o das condições físicas; o da formação docente; e, por fim, o das práticas. Como fundamentação teórica, o trabalho se embasou, principalmente, nas contribuições dos Novos Estudos do Letramento (PAHL \& ROWSELL, 2012), no pressuposto do letramento como prática social (STREET, 1984, 2003; LANKSHEAR \& KNOBEL, 2006, 2011) bem como na proposta da pedagogia dos multiletramentos (CAZDEN et al., 1996; ROJO, 2009, 2012), em especial, quanto à concepção de letramento digital (MARTIN, 2008). No presente trabalho, confrontamos dois dos contextos citados, a saber, o prescritivo e orientativo e o das práticas e a análise permitiu observar os seguintes aspectos: a falta de sintonia entre esses contextos; a inclusão mínima do letramento digital, no currículo escolar; a inserção ainda incipiente e pontual desse letramento nas práticas, além de estas não considera- 
rem as experiências sociodiscursivas e interacionais dos alunos exteriores à escola.

PALAVRAS-CHAVE: Tecnologia educacional. Multiletramentos. Letramento digital.

\section{Considerações iniciais: reflexos das tecnologias na educação}

Nas últimas décadas, observamos que o mundo vem passando por uma transformação tecnológica sem precedentes na história, com a intensificação do processo de globalização das comunicações e o surgimento do que denominamos como a Era da Informação. Assim, considerando esse contexto, Lévy (1998) afirma que vivemos em um tecnocosmo, no qual, a maioria das pessoas produz, transforma e propaga informações, em uma velocidade nunca antes vista. Dessa maneira se, por um lado, expandiu-se o acesso e a disponibilidade em rede de informações das mais diversas áreas do saber, por outro, surgiu o dilema sobre de que modo selecioná-las e convertê-las em conhecimentos.

Acrescentamos a esse fato, que equipamentos tecnológicos digitais de comunicação e informação ganharam versões domésticas e móveis, integrando-se ao nosso cotidiano, e, por conseguinte, as linguagens passaram por um processo de redimensionamento tanto do ponto de vista semiótico quanto dos suportes e da usabilidade, proporcionando o aparecimento de novos e diversificados eventos e práticas de letramento.

Diante desse cenário, torna-se necessário rever paradigmas e, em especial, aqueles referentes aos processos formais de letramento e sua relação com os múltiplos contextos das práticas de linguagem, condição indispensável para proporcionar uma formação aos alunos em sintonia com as demandas sociais e práticas discursivas contemporâneas.

No âmbito da política educacional brasileira, por exemplo, com o propósito de atender às mudanças, como as expostas, a Lei de Diretrizes e Bases da Educação Nacional (LDBEN 9394/96), considerando o momento social vivido pelo país, em seu Art. 35, inclui o Ensino Médio como etapa final da educação básica. Cabe a esse ensino, entre outras finalidades, a de proporcionar a formação geral do indivíduo, bem como a sua preparação para o trabalho e para o exercício da cidadania (BRASIL, 1996). Nesse sentido, as Diretrizes Curriculares 
do Ensino Médio (DCNEM, doravante) propõem uma forma de organização curricular, por meio de um agrupamento das disciplinas por áreas, entre as quais se destaca a de Linguagens, Códigos e suas Tecnologias. Como se afirma no referido documento, a finalidade dessa disciplina é a de propiciar a constituição de diversas competências e habilidades que permitam aos estudantes "aplicar as tecnologias de comunicação e de informação na escola, no trabalho e em outros contextos relevantes para sua vida" (BRASIL, 1998, p. 48).

$\mathrm{Na}$ esteira desses desafios educacionais, os estudos realizados a partir das duas últimas décadas do Século XX, nas áreas de aquisição e desenvolvimento da leitura e escrita, acentuam a necessidade de esse processo transcender a simples aquisição e manejo de técnicas e estratégias, à parte da realidade social em que os indivíduos se encontram inseridos. Essa é, por exemplo, a perspectiva assumida pelos Novos Estudos do Letramento (NEL, doravante), iniciados na Europa e na América do Norte, por estudiosos como Scribner \& Cole (1981), Heath (1983), Street (1984) e Lankshear \&t Knobel (2006, 2011) e Pahl Et Rowsell (2012).

No universo contemporâneo, em que as TIC possibilitaram a emergência de diversas formas de comunicação e de interação, formar indivíduos competentemente letrados requer das escolas que proporcionem o desenvolvimento de diferentes práticas letradas e que incluam os letramentos múltiplos, entre eles, os digitais, já que estes perpassam praticamente todas as atividades humanas hodiernas. Assim, defende-se que se promovam práticas de linguagem nas quais se considere a ativa participação dos sujeitos nas distintas esferas da comunicação humana.

Todavia, desenvolver uma prática educativa integradora dos multiletramentos (CAZDEN et al., 1996) requer, entre outros procedimentos, explorar a multissemiose e a multimodalidade das mídias digitais. Contudo, apesar do reconhecimento da relevância de tal abordagem bem como o discurso oficial em prol da preparação dos alunos para lidarem com o contexto tecnológico e digital, historicamente, há certas limitações materiais, físicas, estruturais e pedagógicas que condicionam ou dificultam a concretização dessas propostas no ensino.

Dada à pertinência das questões anteriormente expostas, nos voltamos para um determinado lócus escolar, tendo em vista como nele se dava a inserção dos letramentos digitais, com ênfase na análi- 
se dos diferentes contextos que condicionam esse processo, quais sejam, o físico (infraestrutura e recursos), o prescritivo e orientativo (documentos), o da formação docente e, finalmente, o das práticas (letramento).

Neste trabalho, revisitamos alguns conceitos centrais relacionados ao letramento e à pedagogia dos multiletramentos, com especial atenção para o letramento digital bem como retomamos alguns dos achados do estudo de caso realizado, especificamente, quanto a dois dos contextos estudados, a saber, o prescritivo e orientativo, denominado campo das intencionalidades, e o do uso das TIC, denominado das práticas. Pretendemos, por meio do confronto de ambos os campos, compreender como se configura o processo de letramento digital nesse universo, de forma situada, considerando em particular esses condicionantes e a relação intrínseca entre os sujeitos e as práticas.

\section{Práticas discursivas e letradas: uma breve reflexão}

0 desenvolvimento das competências de leitura e escrita envolve um processo bem mais amplo que o da alfabetização, já que esta "se ocupa da aquisição da escrita por um indivíduo, ou grupo de indivíduos", enquanto o letramento "focaliza os aspectos sócio-históricos da aquisição de um sistema escrito por uma sociedade" (TFOUNI, 2010, p. 22). De acordo com tal premissa, o letramento compreende a preparação do indivíduo para responder "adequadamente às intensas demandas sociais pelo uso amplo e diferenciado da leitura e da escrita" (SOARES, 2010, p. 20). Assim, esse possui forte conotação social e adquire sentido por meio dos usos situados que os sujeitos fazem de suas habilidades em leitura e escrita.

Avançando em nossas considerações, não podemos esquecer igualmente que as mudanças sociais mais recentes redundaram em certos redimensionamentos quanto à compreensão do letramento, tal como os postulados pelos Novos Estudos do Letramento (NEL, doravante). De acordo com Lankshear \& Knobel (2011), atualmente, ao associarem a palavra "novo" ao letramento, os estudiosos o fazem de duas formas principais, a saber, paradigmática e ontológica, detalhadas a seguir.

Do ponto de visto paradigmático, o "novo" em relação ao letramento associa-se a preocupação com a criação de uma nova abordagem para tratá-lo como um fenômeno social e muitos são os estudos realizados sobre os tipos de práticas, como os de Scribner e Cole 
(1981), Heath (1983), Street (1984), em conformidade com uma perspectiva sociocultural de leitura.

Em relação ao sentido ontológico, "novo" se refere à natureza desses letramentos, ou seja, considera-se que apresentam um caráter diferente em relação aos tradicionais. Esse sentido advém da ideia de que as transformações sociais ocorridas nas tecnologias, meios de comunicações, economia, entre outras, ocasionam alterações na natureza e substância do letramento.

Essa ideia de novo sentido ontológico se relaciona com o surgimento das tecnologias digitais, eletrônicas e, consequentemente, com a emergência de novas formas textuais. Daí, a proposição de que novos letramentos são constituídos de novos fenômenos e, portanto, de natureza diversa daquela do letramento convencional centrada basicamente no texto impresso. Essa concepção se funda no princípio de que as mudanças sociais contemporâneas impactaram as práticas discursivas, transformando as já estabelecidas e ocasionando o surgimento de outras, uma vez que muitas destas envolvem novas formas de produzir, receber e difundir textos, tal como aquelas dos meios eletrônicos e digitais.

Pahl \&t Rowsell (2012), ao sintetizarem as abordagens vigentes, nas duas últimas décadas, no que concerne aos Novos Estudos do Letramento, afirmam que tais trabalhos se fundamentam em dois pressupostos principais: (1) as práticas de letramento são socialmente integradas e não devem ser entendidas isoladamente e (2) o objeto de estudo do letramento não é uma abstração, mas as práticas concretas desses letramentos nas diversas situações sociais em que se inserem.

Assim sendo, esses estudos compartilham os seguintes aspectos:

(1) apontam para a necessidade de os programas de letramento voltados ao processo de letramento formal considerarem os usos da linguagem praticados nos ciclos sociais, comunitários, etc., já que esse processo vai muito além da aquisição de habilidades técnicas necessárias para a utilização da linguagem escrita. De acordo com esta perspectiva, o desenvolvimento do letramento deve contemplar o universo cultural e/ou multicultural em que o letrando vive, sendo esta uma condição para que a aprendizagem de fato ocorra;

(2) despertam os profissionais que atuam com o letramento a buscarem novas formas de desenvolvê-lo, ou seja, a criação de novas práticas de letramento, o que deve ser feito considerando as práticas 
sociais e as necessidades dos alunos, fugindo, consequentemente, de modelos padronizados e desvinculados da realidade dos alunos;

(3) têm contribuído para a criação de modelos de letramento que procuram ajudar os sujeitos a expandirem suas práticas letradas. Assim, uma prática letrada escolar poderia, por exemplo, iniciar com um processo de adaptação às dos alunos adquiridas previamente e, a partir disso, promover a expansão destas dentro de um modelo mais formal. Em consonância com tal perspectiva, as práticas deste último modelo seriam alimentadas pelas mais informais e vice-versa, dentro de um processo contínuo.

Em resumo esses estudos acentuam a necessidade de integração entre as práticas letradas formais desenvolvidas pela escola e as vivências, experiências letradas dos alunos, em espaços extraescolares. Ora, trata-se, na verdade, de condição necessária para o desenvolvimento efetivo da competência comunicativa dos sujeitos em sintonia com as demandas sociais. Sendo assim, essas orientações têm inspirado um olhar mais voltado para os sujeitos, as práticas e as relações entre aqueles como social, cultural e historicamente situadas no âmbito escolar.

\section{Em cena os multiletramentos: algumas ponderações}

Em meio à revolução tecnológica vivenciada na atualidade, e, diante dos impactos provocados, em setembro de 1994, um grupo de dez educadores de diversos países se reuniu em Nova Londres, New Hampshire (EUA), com a finalidade de discutir a situação da pedagogia de letramento. Entre as áreas de interesses e/ou preocupações do grupo se encontravam também as tecnologias de comunicação. A partir das discussões ali realizadas, o grupo relaciona as mudanças sociais com a necessidade de uma nova abordagem para a pedagogia dos letramentos, chamada por eles de multiletramentos. Para esse grupo, a emergência desse enfoque, mais amplo em relação às tradicionais formas de letramento, é necessária, visto que esse considera aspectos tais como, por exemplo, a multiplicidade de canais de comunicações que aumenta continuamente e a diversidade cultural e linguística características da contemporaneidade.

Segundo esses estudiosos, uma abordagem baseada em multiletramentos supera as limitações das tradicionais, 
monolinguísticas e monoculturais, pois foca na formação dos estudantes para negociarem múltiplas linguagens e diferenças culturais no contexto social, aspecto crucial para a vida profissional, cidadã e pessoal. Destacam a ampliação do escopo da pedagogia de letramento para dar conta do contexto social, linguístico e culturalmente diverso, cada vez mais globalizado pelas múltiplas culturas e pela pluralidade de textos que circulam. Além disso, a necessidade de a pedagogia de letramento considerar a emergência de variadas formas de textos oriundos das tecnologias de informação e multimídia, o que implica preparar os alunos para compreenderem e utilizarem as novas formas de representação comuns no ambiente global de comunicações, como as imagens visuais e sua relação com a palavra escrita (CAZDEN et al., 1996, p. 60-61).

Diante dessa conjuntura, para esse grupo, é preciso repensar o currículo, tanto do ponto de vista organizacional quanto do de sua operacionalização. Portanto, uma abordagem centrada nos multiletramentos considera a crescente multiplicidade e integração de modos de construção de significados, em que o texto está relacionado também ao visual, ao auditivo, entre outros. Essa atitude é imprescindivel dentro de um contexto social permeado por meios de comunicação de massa, multimídia, e hipermídia eletrônica, que, no dizer do grupo, estão reformulando continuamente a forma como se usa a linguagem (CAZDEN et al., 1996, p. 63-64).

0 grupo argumenta que essa mudança na pedagogia do letramento atende a uma sociedade multifacetada, marcada pela diversidade produtiva, pelo pluralismo cívico e modos de vida diversificados. Portanto, não se concebe uma pedagogia de letramento centrada na unicidade semiótica, pois a comunicação atual avançou para um nível de multimodalidade sem precedentes, o que demanda uma mudança radical nos processos de letramento no contexto escolar, a fim de que os alunos aprendam a negociar significados (CAZDEN et al., 1996, p. 66-71), em meio a toda essa diversidade linguística e, sobretudo, multissemiótica, multimodal e multimidiática que caracteriza a sociedade contemporânea.

Deste modo, as práticas letradas digitais, no âmbito dos multiletramentos, precisam considerar os gêneros e ferramentas do universo digital como, por exemplo, o bate-papo (chats), fórum, email, blogs, videologs, redes sociais, wikis etc., incorporando-os ao 
currículo, o que representa integrar as vivências extraescolares dos alunos ao fazer pedagógico, conforme defendem os NEL.

Esse panorama ora apresentado remete, na verdade, à necessidade de se promover uma transformação nos processos de letramentos, incluindo-se o letramento digital, o que pode começar pela adequação dos currículos, para que, as práticas de letramento sejam, de fato, plurais, observando, entre outros aspectos, os multiletramentos, tanto no âmbito das multiculturas quanto no das multissemioses.

De acordo com Lankshear e Knobel (2011), do início da década de setenta ao início da de noventa, do século passado, o perfil e o status do letramento mudou drasticamente em muitos sistemas educativos modernos, especialmente nos países anglo-americanos desenvolvidos, em função da disponibilidade e da adoção pelas massas, das sofisticadas tecnologias e redes eletrônicas, como é o caso da Internet. Segundo tais autores, esse fato provavelmente também explique porque desde meados dos anos 90, a preocupação pelo desenvolvimento do letramento digital tem estado presente em muitos documentos de política de educação e tem sido considerado o objetivo educacional principal.

Para Martin (2008, p. 151), vivemos em uma sociedade em que as ferramentas digitais, frequentemente, mediam nossas ações, nas mais diversas esferas sociais. Dessa maneira, o letramento digital é um poderoso instrumento para que o indivíduo possa entender sua própria relação com o digital, cuja compreensão envolve o conhecimento do papel desse universo no desenvolvimento pessoal, a fim, não apenas de dominá-lo, mas também, colocá-lo à disposição dos seus objetivos e aspirações.

Ainda conforme Martin (2008, p. 167-174), o letramento digital envolve três níveis, centrados no uso do computador: 1. o da técnica, referente ao domínio de competências digitais; 2 . o da aplicação contextualmente apropriada das ferramentas digitais e 3. o da reflexão crítica, da compreensão do impacto transformador, humano e social, das ações digitais.

Assim, partimos do pressuposto de que é por meio do desenvolvimento desses níveis de letramento digital, no contexto escolar, quer seja de modo disciplinar ou interdisciplinar, que se caminhará para a formação de indivíduos letrados digitalmente. Por conseguinte, para alcançar esse fim é preciso ter em conta as contribuições de uma proposta pedagógica centrada nos multiletramentos e conside- 
rar o universo das práticas letradas dos alunos fora da escola, práticas que são cada vez mais digitais, híbridas e singularizadas. Além desse aspecto, não se pode ignorar questões de ordem física, estrutural (recursos materiais) e pedagógicas (recursos humanos). Daí, portanto, a necessidade de pensarmos de forma conjuntural e considerarmos os diversos contextos condicionantes para o desenvolvimento do letramento digital no âmbito escolar.

\section{0 estudo de caso: caminhos que se vislumbram nos distintos contextos}

Tendo em vista o contexto explicitado, fomos levados a indagar acerca dos possíveis caminhos para a inclusão do letramento digital no âmbito das práticas escolares. Com essa finalidade, optamos por estudar como uma escola pública de uma capital do nordeste do país vinha incluindo os multiletramentos e, em especial, o letramento digital, na etapa final da educação básica, dada a sua importância para a formação discente, conforme as razões já aludidas.

Esclarecemos que, tendo em vista a natureza e os objetivos do trabalho, optamos por realizar um estudo de caso. É importante acentuar que uma das peculiaridades de um estudo desse tipo diz respeito à possibilidade de utilização de uma variedade de fontes de informações (LUDWIG, 2009), o que permite o emprego de diversificadas técnicas de pesquisa, possibilitando uma visão e compreensão mais ampla do fenômeno em estudo, como pretendíamos.

Além do mencionado, a escolha do objeto da pesquisa e, consequentemente, a opção pelo estudo de caso emergiu do fato de as práticas letradas desenvolvidas nas escolas serem muitas vezes alheias ao contexto social contemporâneo, altamente tecnológico, hipermidiático e multissemiótica. Acreditamos, assim, que somente um estudo minucioso permitiria compreender o estado do fenômeno, no lócus de estudo, para, a partir daí, podermos dar uma contribuição mais efetiva para os trabalhos empreendidos na área dos multiletramentos, com ênfase para o letramento digital.

Neste artigo, privilegiaremos, dentre os diversos contextos analisados, o prescritivo e orientativo e o das práticas, ou seja, respectivamente, o campo das intencionalidades e o campo das práticas. Assim, confrontamos o que prescrevem e/ou orientam os documentos parametrizadores do ensino, por um lado, e por outro, que práticas 
de letramento digital são familiares aos sujeitos (alunos e professores). Com esse propósito, recorremos à análise documental e à aplicação de questionários, alvos de nosso exame.

Portanto, quanto ao contexto prescritivo e orientativo, analisamos como os documentos oficiais e os documentos escolares consideravam o letramento digital e como sugeriam o seu desenvolvimento na escola. Recorremos à pesquisa documental das seguintes fontes: Leis de Diretrizes e Bases de Educação - LDBEN 9394/96, Diretrizes Curriculares Nacionais do Ensino Médio - DCNEM, Parâmetros Curriculares Nacionais do Ensino Médio - PCNEM, Referencial Curricular Estadual de Língua Portuguesa - RCELP, Projeto PolíticoPedagógico - PPP e Planos de Ensino de Língua Portuguesa - PELP.

Já quanto ao contexto das práticas, investigamos a relação dos alunos com as tecnologias digitais, em especial o computador e a Internet, fora da escola e, em especial, relacionando-as com as práticas letradas digitais promovidas na escola, mediadas pelos docentes. Assim, relataremos aqui alguns dados obtidos dos questionários aplicados, que nos permitiram conhecer tais práticas do ponto de vista dos docentes e dos alunos. Convém notar que dado o grande número de turmas e, consequentemente, de alunos da escola, aplicamos questionários por amostragem, contemplando-se nove docentes, três por turno e série, e duzentos e setenta alunos, sendo trinta por turma.

\section{Alguns achados: intencionalidades $x$ práticas}

Nesta seção, apresentaremos alguns resultados obtidos por meio da análise dos dados gerados, tendo em vista os dois contextos descritos no item anterior, quais sejam, o prescritivo e orientativo, e o das práticas, confrontando-se estas últimas com as experiências dos alunos fora da escola.

\subsection{Campo das intencionalidades: o contexto prescritivo e orientativo}

A investigação no primeiro contexto se deu por meio da análise dos documentos prescritivos e orientativos externos e internos à escola. No âmbito externo, a análise dos documentos como LDBEN 9394/96, DCNEM, PCNEM e RCELP, evidenciou que eles não somente apresentam prescrições e orientações coerentes com as transformações tecnológicas e sociais ocorridas nas últimas décadas, especial- 
mente no âmbito das TIC, mas também procuram integrá-las ao novo momento educativo. Além disso, eles preconizam que, no contexto das práticas com linguagens, o desenvolvimento do letramento ocorra em conformidade com uma perspectiva sociocultural. Sugerem, igualmente, uma abordagem como a dos multiletramentos, o que por sua vez remete a Cazden et. al. (1996) e enfatizam a necessidade de potencializar o letramento digital, o que lembra Martin (2008).

Interessa acentuar que os documentos desse primeiro subcontexto apresentam uma sintonia com os recentes estudos do letramento, embora esses não sejam explicitamente mencionados. Neste sentido, notamos uma consonância entre tais documentos em relação à abordagem do letramento digital como parte das práticas de linguagens centradas nos multiletramentos. Essas são decorrentes, por sua vez, das transformações tecnológicas que produziram mudanças substanciais em distintas esferas da comunicação e também da nova perspectiva de abordagem do letramento como prática social. Assim, por exemplo, na LDB, esses aspectos são contemplados de forma geral, sendo ampliados nas DCNEM, e apresentados já de modo bem abrangente nos PCNEM e no RCELP.

É bom ressalvar que, em relação específica ao letramento digital, os documentos, a exemplo dos PCNEM e do RCELP, não chegam a considerar uma proposta de letramento detalhada quanto à proposta por Martin (2008), mas há indícios de que caminham nessa direção.

Quando se passa para os documentos do contexto interno, no entanto, percebemos uma quebra na sintonia ora apresentada, uma vez que, no Projeto Político Pedagógico, foram identificadas algumas referências genéricas sobre a necessidade de o processo educativo incluir as tecnologias emergentes, tendo em vista as mudanças sociais, diferentemente do que ocorre na LDBEN e nas DCNEM. Neste documento ainda se afirma que a concepção de currículo, o planejamento e a avaliação devem ser norteados pelos PCNEM e pelo RCELP. Já no PELP a linguagem digital não é considerada explicitamente e, entre os gêneros digitais, apenas o e-mail é citado. Contudo, na justificativa refere-se à importância do estudo e da compreensão das múltiplas linguagens e de seus mecanismos expressivos no processo de formação do aluno, para responder às exigências da sociedade e da vida cidadã, no rol de competências e habilidades a serem desenvolvidas pelos alunos ao longo das três séries do Ensino Médio e de seus respectivos conteúdos. 
Há, pois, do ponto de vista do contexto prescritivo e orientativo, uma ruptura entre os documentos do contexto externo e os do interno. Esse fato sugere que as prescrições e orientações oficiais, tanto as da esfera nacional quanto as da estadual, sendo esta última a que a escola-campo de estudo está vinculada, acabam não chegando ao seu destino final, a instituição escolar. Neste sentido, os PPP e PELP, norteadores das práticas pedagógicas dos professores, neste caso específico, das práticas letradas não explicitam ou propõem formas concretas de exploração para esses letramentos.

\subsection{Campo das práticas: o uso das TIC em prol do} letramento digital dos alunos

Considerando-se inicialmente a relação dos alunos com as TIC, constatamos que em torno de $85 \%$ deles possuíam computador em suas residências, sem contar os possuidores de smartphones, que igualmente propiciam a leitura e a escrita na tela (embora de modo mais limitado), além dos que não dispunham dessas tecnologias, mas a elas tinham acesso em Lan Houses e em residências de amigos ou parentes.

No que tange ao acesso desses jovens à Internet, verificamos que $73,0 \%$ deles a acessavam em suas próprias residências, sem considerar os outros 34,8\% que disseram que o faziam em Lan Houses, residências de amigos e em outros locais, ou seja, 81,5\% desses sujeitos afirmaram aceder à Internet diariamente ou mais de uma vez por semana. Ora, isso significa dizer que, de algum modo, estão imersos nessa sociedade em rede que emerge com a Internet e, por conseguinte, inseridos na cibercultura, de acordo com a denominação de Lévy (1999).

Por sua vez, a variedade de recursos e ferramentas da Internet, bem como a de gêneros textuais em ambiente digital a que esses jovens têm acesso (redes sociais, sites de busca, notícias, comunicadores instantâneos, bate-papos, vídeos, jogos, e-mail, etc.), confirmou que, dentro desse universo eles desenvolviam práticas específicas de letramento digital. Estas, se conhecidas pelos docentes e por eles consideradas, em conformidade com a perspectiva dos novos letramentos (conforme LANKSHEAR E KNOBEL, 2011; PAHL \& ROWSELL, 2012) e exploradas com base em uma abordagem como a dos multiletramentos (de acordo com CAZDEN et al., 1996), poderiam contribuir para potencializar a formação cidadã dos alunos e ampliar seu letramento, em direção ao âmbito digital. 
Os dados, por exemplo, mostraram que, nessas práticas letradas fora da escola, 50,4\% dos sujeitos priorizavam o uso das redes sociais, cujo objetivo primeiro é o de estabelecimento e manutenção de relações sociais, ficando as demais práticas relegadas a um segundo plano pela maioria. 0 desenvolvimento do letramento digital considerando tais particularidades socioculturais (conforme PAHL \& ROWSELL, 2012; STREET, 1984) poderia, por exemplo, contribuir para que os alunos se valessem das práticas letradas externas à escola, e, assim, ampliassem o uso de outras ferramentas, recursos e gêneros da Internet que lhes permitissem transformar esse universo de informações em conhecimento efetivo. Desse modo, práticas letradas escolares e extraescolares seriam integradas, o que poderia tornar o ensino mais atraente e significativo. E, além desse ponto, caminhar em direção à ampliação do letramento digital, de acordo com essa perspectiva, implica circular e interagir nos ambientes virtuais de modo crítico e ético, explorando suas potencialidades para promover diversas aprendizagens.

Outro ponto a salientar é que a análise dos dados mostrou que os docentes, em sua maioria, não se orientam por uma perspectiva sociocultural como as propostas pelos NEL quanto aos letramentos contemporâneos.

Além do exposto, o uso tanto da Informática quanto da Internet, no âmbito interno da escola, se limita a uma minoria dos docentes, que por sua vez o faziam com uma periodicidade mensal e bimestral. Essa subutilização de ferramentas e recursos tecnológicos foi reforçada pelo fato de que a proposição de atividades educativas para realização em casa empregando tais recursos e ferramentas não ocorria com frequência e nem sempre as atividades e usos eram devidamente orientados, sob o ponto de vista didático, com vista a favorecer o processo de letramento digital e as aprendizagens mediadas pelas tecnologias.

Quando se tratou do uso específico dos recursos e ferramentas ora mencionados, os dados revelaram que se focalizavam os geradores de apresentação utilizados, na maioria dos casos, como simples substitutos dos quadros de giz, ao gerar apresentações às vezes centradas na linguagem verbal (monomodal) e servido como recurso auxiliar para aulas expositivas, distantes da abordagem requerida pelos multiletramentos (CAZDEN et al., 1996). Além desse fato, o material produzido pelo próprio professor, o que ocorria segundo foi infor- 
mado pela maioria deles, tinha pouquíssimas possibilidades de contribuir para a ampliação do letramento digital dos alunos, dadas as suas limitações na elaboração e manejo.

Ademais, recordamos que atividades envolvendo editores de textos, por exemplo, isoladamente apresentam baixos índices de uso, o que também compromete e/ou dificulta a efetivação do letramento digital no âmbito escolar. Esses aspectos poderiam ser mais bem explorados pelos docentes nas práticas de letramento com o fim de viabilizar o desenvolvimento do letramento digital, por meio da aplicação contextualizada das competências e habilidades relativas às tecnologias digitais, relacionadas ao primeiro nível do letramento digital (MARTIN, 2008).

Tendo em vista que o indivíduo letrado precisa estar preparado para atender às diferentes demandas sociais que requerem o uso da leitura e da escrita (SOARES, 2010), em se tratando de letramento digital é preciso levar os alunos a lidarem com as diversas ferramentas digitais e modalidades textuais do âmbito do computador e da Internet para que ele possa utilizá-las de forma competente e consciente (MARTIN, 2008).

Além dos aspectos aludidos, quanto ao uso da Internet, os sites de busca e os institucionais diversos (no conjunto das ferramentas e recursos da Internet) e a realização de pesquisas (no âmbito das atividades) foram os mais utilizados na operacionalização do currículo. Esse fato sugere que se trata de um processo centralizado tanto no uso de tais recursos e ferramentas, quanto na realização das atividades, excluindo tantos outros que poderiam dinamizar a mediação pedagógica e propiciar o letramento digital dos alunos. Notamos, desse modo, a exclusão de uma diversidade de recursos e ferramentas da Internet, com as quais, atividades diversas, dentro de uma perspectiva de multiletramentos (CAZDEN et al., 1996) poderiam ser realizadas.

Notamos ainda que a leitura e exploração do hipertexto não foram consideradas por quase metade dos docentes, ainda que este possua características próprias (KOMESU, 2005; MARCUSCHI, 2005) e requeira habilidades especificas não somente para quem navega por ele de modo exploratório apenas, mas também para quem se propõe a usá-lo construtivamente, estabelecendo sentidos com base nas múltiplas semioses que o constituem.

De modo análogo, constatamos que um pouco mais da metade dos docentes trabalhava com o ensino da escrita em ambientes virtu- 
ais excluindo os demais alunos desse processo. Considerando que no contexto social permeado por meios de comunicação de massa, multimídia, e hipermídia eletrônica, a forma como se usa as linguagens está sendo continuamente reformulada (CAZDEN et al., 1996, p. 63-64), é necessária a inclusão e efetivação curricular do ensino da escrita presente nesse tipo de ambiente. Essa inclusão se explica porque os próprios docentes reclamam das interfaces que os alunos fazem entre a escrita convencional e aquela que ocorre nesse novo ambiente, uma vez que para esses docentes, há prejuízo para o primeiro tipo. Portanto, incluir essa discussão ao refletir-se e propor currículos e definir objetivos de ensino e aprendizagem pode contribuir para o uso consciente e crítico da linguagem, inclusive, no que diz respeito à dos ambientes virtuais, em consonância com as demandas de uma sociedade cada vez mais tecnológica.

Assim, as práticas de letramento desenvolvidas na escola em questão não contemplavam o letramento digital de modo holístico e sistemático, já que estavam longe de alcançar os três níveis que o compõe, quais sejam, o da técnica, o do domínio de competências digitais; o da aplicação contextualizada das ferramentas digitais e o da reflexão crítica, da compreensão do impacto das ações digitais que o constituem, conforme proposto por Martin (2008). Na verdade, sequer os processos constitutivos do primeiro nível descrito foram objeto de trabalho no âmbito do currículo da escola.

\section{Considerações finais}

Em face do tratado, consideramos que para que o letramento digital se desenvolva minimamente na escola pesquisada, necessário se faz sua inclusão efetiva no currículo escolar, articulando-se objetivos, competências e habilidades, recursos e conteúdos. Além, evidentemente, de uma clareza quanto às formas de conduzir tarefas que viabilizem o desenvolvimento dos níveis de letramento digital, já citados.

Considerando a presente análise, em especial no concernente ao contexto das práticas, sugere-se que a ausência de uma abordagem centrada nos multiletramentos (Cazden et al., 1996) contribuiu em grande parte para que o letramento digital ficasse à margem no processo de desenvolvimento das práticas de linguagens nesta escola.

A efetivação de todas as etapas do estudo de caso permitiu-nos a construção de uma visão ampla e, de certo modo, profunda do 
letramento digital e, consequentemente, das linguagens e dos gêneros emergentes.

Vemos, pois, que a relevância e necessidade do letramento digital estão de fato expressas nos documentos oficiais prescritivos e orientativos externos, mas o mesmo não se pode dizer em relação aos do âmbito interno da escola, em que as referências ao objeto de estudo ou inexistem ou ainda são muito superficiais e tímidas. Neste sentido, o contexto físico e o da formação acabam limitando o desenvolvimento de práticas letradas digitais, na escola, especificamente nas aulas de Língua Portuguesa, em que ainda são bastante pontuais e reduzidas, uma vez que não se aproveitam e valorizam as experiências prévias dos alunos com as TIC a fim de fomentar as diversas aprendizagens.

Por fim, concluímos que o desenvolvimento do letramento digital está condicionado por diversos contextos, alguns deles aludidos aqui. Acreditamos que por meio da observância deles, da complexa articulação entre tais contextos, é possível compreender de forma multidimensional os fatores que interferem na inclusão do letramento digital na escola. Sendo assim, torna-se necessário aprofundar a análise conjuntural, tendo em vista como os diversos contextos se relacionam e como podemos introduzir mudanças nesse circuito. Esperamos, dessa maneira, ao enfatizar a dissonância entre o campo da intencionalidade e o da prática problematizar como, paradoxalmente, o letramento digital ainda é um estranho no ninho (ou nas redes).

\section{ABSTRACT}

The studies about literacy have pointed to the necessity of reconsidering the ontology and paradigms that are related to the comprehension of several literacy practices, their relationship with the subject in the contemporary society as in the case of the practice that involve technologies and digital resources in scholar environments. Thus, aiming to investigate how the digital literacy has been introduced in the teaching of languages, in the scope of basic education, a survey in a public school was conducted. Such survey was a case study in which the relationship between different conditional contexts of digital literacy insertion was evaluated like, for example, the prescriptive and directive; 
the infrastructure; the teacher background and, at the end, the practices themselves. The theoretical foundation to conduct this survey relied on the novel studies on literacy (PAHL \& ROWSELL, 2012), the presumptive literacy as social practice (STREET, 1984, 2003; LANKSHEAR \& KNOBEL, 2006, 2011) and the pedagogic proposal of multi-literacy (CAZDEN et al., 1996; ROJO, 2009, 2012), especially in relation to the conception of digital literacy (MARTIN, 2008). Summarily, in our present work, we examined two of these cited contexts, namely, the prescriptive/directive and the practices, from which the analysis has allowed the following aspects to be observed: lack of consonance between these contexts; minimal insertion of the digital literacy in the scholar curriculum; incipient and very punctual insertion of these literacy practices; additionally, these contexts did not take into account the socio-discursive and interactive experiences from the students outside the school.

KEY WORDS: Educational Technology. Multiliteracies. Digital literacy.

\section{REFERÊNCIAS}

BRASIL. Lei no 9394, de 20 de dezembro de 1996. Brasília, DF: Presidência da República, 1996. Disponível em <http://www.planalto.gov.br/ccivil_03/Leis/ L9394.htm>. Acesso em: 16 jan. 2011.

BRASIL. Conselho Nacional de Educação. Resolução CEB n 3, de 26 de junho de 1998. Institui as Diretrizes Curriculares Nacionais para o Ensino Médio. Disponivel em: $<$ http://edutec.net/Leis/Educacionais/eddirem.htm> Acesso em: 20 fev. 2012.

BRASIL. MINISTÉRIO DA EDUCAÇÃO. PCN+ Ensino Médio - Orientações Educacionais Complementares aos Parâmetros Curriculares Nacionais: Linguagens Códigos e suas Tecnologias. Brasília: MEC; SEMTEC, 2002.

BRASIL. SECRETARIA DE EDUCAÇÃO BÁSICA. Linguagens Códigos e suas Tecnologias: Orientações Curriculares para o Ensino Médio. Brasília: MEC/ SEB, 2006. Vol. 1.

CAZDEN, Courtney, COPE, Bill; FAIRCLOUGH, Norman; GEE, Jim et al. A 
pedagogy of multiliteracies: designing social futures. Havard Educational Review, [Cambridge], v. 66, n 1, p. 60-92, Spring, 1996.

HEATH, Shirley Brice. Ways with words. Cambridge: Cambridge University Press, 1983.

KOMESU, Fabiana. Pensar em hipertexto. In: ARAÚJO, Júlio César; BIASIRODRIGUES, Bernardete. Interação na Internet: novas formas de usar a linguagem. Rio de Janeiro: Lucerna, 2005, p. 87-108.

LANKSHEAR, Colin; KNOBEL, Michele. New Literacies: everyday practices and classroom learning. 2nd. ed. Maidenhead and New York: Open University Press, 2006.

New literacies: everyday practices and social learning. 3rd ed. England: Open University Press, 2011.

LÉVY, Pierre. A máquina universo: criação, cognição e cultura informática. Trad.: Bruno Charles Magne. Porto Alegre, ArtMed, 1998.

LUDWIG, Antonio Carlos Will. Fundamentos e prática de metodologia científica. Petrópolis, RJ: Vozes, 2009.

MARANHÃO. Referenciais Curriculares: Ensino Médio. São Luís: Secretaria de Estado da Educação, 2010.

MARCUSCHI, Luiz Antônio. A coerência no hipertexto. In: COSCARELLI, Carla Viana; RIBEIRO, Ana Elisa (Org.) Letramento digital: aspectos sociais e possibilidades pedagógicas. Belo Horizonte: Ceale; Autêntica, 2005, p.185207.

MARTIN, Allan. Digital literacy and the "Digital Society". In: LANKSHEAR, Colin; KNOBEL, Michele (Eds.) Digital Literacies: concepts, policies and practices. New York: Peter Lang Publishing, 2008, p. 151-176.

PAHL, Kate; ROWSELL, Jennifer. Literacy and Education: The New Literacy Studies in the classroom. 2nd ed. London: Sage Publications Ltd., 2012.

PEREIRA, Eliúde Costa Pereira. Tecnologia educacional e letramento digital: um estudo de caso de vários contextos de uma escola pública. Fortaleza, 2014. 294p. Tese (Doutorado) - Universidade Federal do Ceará, Centro de Humanidades, Departamento de Letras Vernáculas, Programa de Pós-Graduação em Linguística, Fortaleza, 2014.

SCRIBNER, Sylvia \&t Michael Cole. The Psycology of literacy. Cambridge, MA: Harvard University Press, 1981.

SOARES, Magda. Letramento: um tema em três gêneros. 4a ed. Belo Horizonte: Autêntica Editora, 2010.

STREET, Brian Vincent. Literacy in theory and practice. Cambridge: Cambridge University Press, 1984. 
. What's "new" in New Literacy Studies?: critical approach to literacy in theory and practice. Current Issues in Comparative Education, Columbia University, New York, Vol. 5. n. 2, May 2003. Disponível em: http:// people.ufpr.br/ clarissa/pdfs/NewInLiteracy_Street.pdf> Acesso em: 22 mai. 2013.

TFOUNI, Leda Verdiani. Letramento e alfabetização. 9a ed. São Paulo: Cortez, 2010.

Recebido em 30 de maio de 2015

Aprovado em 03 de junho de 2015 